\title{
Predictive factors for recurrence and clinical outcomes in patients with chronic subdural hematoma
}

\author{
Myung-Hoon Han, MD, ${ }^{2}$ Je II Ryu, MD, ${ }^{2}$ Choong Hyun Kim, MD, PhD, ${ }^{2}$ Jae Min Kim, MD, PhD, ${ }^{2}$ \\ Jin Hwan Cheong, MD, PhD, ${ }^{2}$ and Hyeong-Joong Yi, MD, $\mathrm{PhD}^{1}$ \\ 1Department of Neurosurgery, Hanyang University Medical Center, Seoul; and 2Department of Neurosurgery, Hanyang University \\ Guri Hospital, Gyonggi-do, Korea
}

\begin{abstract}
OBJECTIVE Chronic subdural hematoma (CSDH) is a common type of intracranial hemorrhage in elderly patients. Many studies have suggested various factors that may be associated with the recurrence of CSDH. However, the results are inconsistent. The purpose of this study was to determine the associations among patient factors, recurrence, and clinical outcomes of CSDH after bur hole surgery performed during an 11-year period at twin hospitals.

METHODS Kaplan-Meier analysis was performed to evaluate the risk factors for CSDH recurrence. Univariate and multivariate Cox proportional hazards regression analyses were used to calculate hazard ratios with $95 \% \mathrm{Cls}$ for CSDH recurrence based on many variables. One-way repeated-measures ANOVA was used to assess the differences in the mean modified Rankin Scale score between categories for each risk factor during each admission and at the last follow-up.
\end{abstract}

RESULTS This study was a retrospective analysis of 756 consecutive patients with CSDH who underwent bur hole surgery at the Hanyang University Medical Center (Seoul and Guri) between January 1, 2004, and December 31, 2014. During the 6-month follow-up, 104 patients (13.8\%) with recurrence after surgery for CSDH were identified. Independent risk factors for recurrence were as follows: age > 75 years (HR 1.72, 95\% Cl 1.03-2.88; $p=0.039$ ), obesity (body mass index $\geq 25.0 \mathrm{~kg} / \mathrm{m}^{2}$ ), and a bilateral operation.

CONCLUSIONS This study determined the risk factors for recurrence of CSDH and their effects on outcomes. Further studies are needed to account for these observations and to determine their underlying mechanisms.

https://thejns.org/doi/abs/10.3171/2016.8.JNS16867

KEY WORDS body mass index; chronic subdural hematoma; recurrence; modified Rankin Scale; trauma; vascular disorders

$\mathrm{C}$ HRONIC subdural hematoma (CSDH) is a common type of intracranial hemorrhage in elderly patients, with a recurrence rate after bur hole surgery ranging from $9.2 \%$ to $26.5 \% .{ }^{35}$ Numerous studies have reported various potential risk factors for CSDH recurrence, although their results are inconsistent., ${ }^{1,2,6,9,12,15,21-24,31,35,37}$ Cerebral atrophy is a well-known risk factor for occurrence and/or recurrence of CSDH. ${ }^{18,38,39}$ Despite the fact that many studies have reported an association between body mass index (BMI) and brain atrophy, there have been no studies regarding the association between BMI and recurrence or clinical outcomes of CSDH. ${ }^{5,7,8,10,16,20,25,28,34} \mathrm{We}$ hypothesized that the cerebral atrophy associated with higher BMI may influence CSDH recurrence.

The purpose of the present study was to determine the associations among patient factors, recurrence, and clini- cal outcomes of CSDH after bur hole surgery performed during an 11-year period at twin hospitals.

\section{Methods}

\section{Patients and Definition of CSDH Recurrence}

Initially, we collected data on 794 patients with CSDH from the Traumatic Brain Injury registry at our twin hospitals (Seoul, $n=439$; Guri, $n=355$ ). We then excluded 38 patients ( 21 for missing data, 13 for postoperative acute intracranial bleeding that required surgery, and 4 for sudden cardiac arrest). Finally, we retrospectively analyzed the cases of 756 consecutive patients with CSDH who underwent bur hole surgery at the Hanyang University Medical Center (Seoul and Guri) between January 1, 2004, and December 31, 2014. Diagnosis was confirmed by head CT 
scan or MR image in all patients. After we obtained data in patients with CSDH from the registry, all medical records (including operative records) were reviewed by 2 specialized research teams using an electronic medical records system database.

We defined recurrence as a radiologically confirmed $\mathrm{CSDH}$, which developed in the ipsilateral subdural space within 6 months of the initial surgery and produced neurological deficits that required reoperation. ${ }^{4}$

This study was approved by the institutional review boards of Hanyang University Medical Center in both Seoul and Guri.

\section{Surgical Procedures and General Management}

A standard 1- or 2-bur hole craniostomy was performed in all cases with or without saline irrigation under local or general anesthesia in both hospitals. All patients who had bilateral CSDH surgery received each bur hole craniostomy in a single operation. We treated each bilateral hematoma as 1 case and performed the same procedure on both sides. We inserted closed-system drainage in all cases and placed the drain approximately $30-50 \mathrm{~cm}$ below head level. In most cases, the drain was removed within 3 days. We performed repeat surgery with the same procedure in the recurrent patient group. We did not use preoperative dexamethasone in any cases.

Antiplatelet or anticoagulant agents were discontinued before surgery in all cases. In patients with elevation of the international normalized ratio on admission, we routinely administered intravenous vitamin $\mathrm{K}$ before surgery. Antiplatelet or anticoagulant agents were usually restarted 1 month from the day of surgery.

Routine follow-up CT scans were acquired immediately and 1 week after surgery. Patients without complications were generally discharged within 10 days.

\section{BMI Measurement and Classification}

Body weight and height were measured and recorded by the nurse on admission. If this was not possible, we used the most recent weight measurements obtained from the patients or their relatives. BMI was calculated as weight/(height $\times$ height) and expressed in $\mathrm{kg} / \mathrm{m}^{2}$. Based on the West Pacific-Asian criteria of obesity ${ }^{36}$ we divided all patients into 4 groups based on BMI: $<18.5 \mathrm{~kg} / \mathrm{m}^{2}$ (underweight), $18.5-22.9 \mathrm{~kg} / \mathrm{m}^{2}$ (normal), $23.0-24.9 \mathrm{~kg} / \mathrm{m}^{2}$ (overweight), and $\geq 25.0 \mathrm{~kg} / \mathrm{m}^{2}$ (obese). In addition, we divided obese patients $\left(\geq 25.0 \mathrm{~kg} / \mathrm{m}^{2}\right.$ ) into groups of $25.0-27.4$ and $\geq 27.5 \mathrm{~kg} / \mathrm{m}^{2}$ to more specifically investigate the association between recurrence and BMI in obese patients (data shown in the Supplemental Material). A recent study supports the use of this specific BMI classification for the Asian population. ${ }^{14}$

\section{Clinical Patient Factors}

Hypertension and diabetes were defined as previous use of antihypertensive/antidiabetic medication, medical records indicating a history of hypertension/diabetes, or patient/guardian self-reporting. These methods were also used to determine other medical history. We defined malignancy as any cancer in any part of the body, including the CNS, lymph nodes, soft tissue, bone marrow, and so on. We defined a history of cerebrovascular disease based on medical history and review of neuroimaging. A history of smoking was defined to include current smokers, and a history of drinking was classified into 3 groups: never or less than once a month, moderate (once a month to less than once a week), and frequent (weekly or more). We also investigated the use of antithrombotic medications, including antiplatelet agents (aspirin and/or clopidogrel), anticoagulants (warfarin), and combined use, in all patients.

\section{Radiological Variables}

All CT scans and MR images of 756 patients with CSDH were assessed by 2 senior neurosurgeons (H.J.Y. in Seoul and J.H.C. in Guri). We measured the width of the hematoma and the midline shift immediately before surgery and evaluated the side of the operation after surgery. We also evaluated encephalomalacic changes that may have indicated a previous brain hemorrhage or ischemic damage and classified these as cerebrovascular disease.

\section{Outcome Measures}

We assessed the 6-month recurrence rate after surgery for CSDH in both hospitals. Fifty-five patients did not return for the 6-month follow-up examination, yielding a completion rate of $92.7 \%$. We also investigated the modified Rankin Scale (mRS) score of all patients at admission and at the last follow-up.

\section{Statistical Analysis}

Baseline characteristics of patient data are presented as the mean $\pm \mathrm{SD}$ or the median (interquartile ranges). Discrete variables are expressed as count (percentage). The $\chi^{2}$ test for dichotomous variables and the Student $t$-test for continuous variables were used to assess clinical differences between patients with and without recurrence.

Time-to-event (recurrence) analysis was performed to evaluate risk factors for CSDH recurrence using Kaplan-Meier curves, with censoring of patients who died or were lost to follow-up. We used univariate Cox proportional hazards regression analyses to calculate hazard ratios with 95\% CIs for CSDH recurrence based on several variables. Subsequently, sex, age, and covariates that were significant at $\mathrm{p}<0.20$ in univariate analysis were included in multivariate analysis to test for an independent association with CSDH recurrence..$^{33}$ We also presented the multivariate HRs adjusted for the 5 categorical groups of BMI in Table I in the Supplemental Material.

The mRS score is presented for each admission and the last follow-up as the mean \pm SD based on the risk factors for $\mathrm{CSDH}$ recurrence. A paired t-test was used to compare the differences between the mean mRS score at admission and the last follow-up. We used 1-way repeated-measures ANOVA to assess the differences in the mean mRS score between categories of each risk factor at each admission and last follow-up. Multiple comparison Tukey-adjusted $\mathrm{p}$ values were reported.

Statistical analyses were performed using $\mathrm{R}$ version 3.1.2 and SPSS for Windows, version 22.0 software (IBM Corp.). 
TABLE 1. Characteristics of patients with CSDH included in the study

\begin{tabular}{|c|c|c|c|c|}
\hline Variable & No Recurrence & Recurrence & Total & $\mathrm{p}$ Value \\
\hline No. $(\%)$ & $652(86.2)$ & $104(13.8)$ & $756(100)$ & \\
\hline Follow-up in mos, mean \pm SD & $12.1 \pm 6.3$ & $13.6 \pm 5.5$ & $12.3 \pm 6.3$ & 0.019 \\
\hline Sex, $M$, no. $(\%)$ & $491(75.3)$ & $83(79.8)$ & $574(75.9)$ & 0.382 \\
\hline Age in yrs, mean $\pm S D$ & $67.8 \pm 8.2$ & $68.6 \pm 8.5$ & $67.9 \pm 8.3$ & 0.314 \\
\hline Age group, yrs, no. (\%) & & & & 0.033 \\
\hline$<65$ & $220(33.7)$ & $27(26.0)$ & $247(32.7)$ & \\
\hline $65-74$ & $292(44.8)$ & $43(41.3)$ & $335(44.3)$ & \\
\hline$\geq 75$ & $140(21.5)$ & $34(32.7)$ & $174(23.0)$ & \\
\hline Height in $\mathrm{cm}$, mean $\pm \mathrm{SD}$ & $165.6 \pm 7.1$ & $165.4 \pm 7.5$ & $165.6 \pm 7.2$ & 0.781 \\
\hline Weight in $\mathrm{kg}$, mean $\pm \mathrm{SD}$ & $61.8 \pm 11.8$ & $62.8 \pm 12.6$ & $61.9 \pm 11.9$ & 0.407 \\
\hline $\mathrm{BMI}$ in $\mathrm{kg} / \mathrm{m}^{2}$, median (IQR) & $22.7(20.3-24.9)$ & $23.3(19.7-25.7)$ & $22.9(20.3-25.0)$ & 0.282 \\
\hline BMI classification, no. (\%) & & & & 0.128 \\
\hline$<18.5 \mathrm{~kg} / \mathrm{m}^{2}$, underweight & $94(14.4)$ & $17(16.3)$ & $111(14.7)$ & \\
\hline $18.5-22.9 \mathrm{~kg} / \mathrm{m}^{2}$, normal & $248(38.0)$ & $28(26.9)$ & $276(36.5)$ & \\
\hline $23.0-24.9 \mathrm{~kg} / \mathrm{m}^{2}$, overweight & $156(23.9)$ & $26(25.0)$ & $182(24.1)$ & \\
\hline$\geq 25.0 \mathrm{~kg} / \mathrm{m}^{2}$, obese & $154(23.6)$ & $33(31.7)$ & $187(24.7)$ & \\
\hline \multicolumn{5}{|l|}{ Medical history, no. (\%) } \\
\hline Hypertension & $279(42.8)$ & $40(38.5)$ & $319(42.2)$ & 0.469 \\
\hline Diabetes & $172(26.4)$ & $35(33.7)$ & $207(27.4)$ & 0.154 \\
\hline Heart disease & $112(17.2)$ & $20(19.2)$ & $132(17.5)$ & 0.709 \\
\hline Liver disease & $66(10.1)$ & $15(14.4)$ & $81(10.7)$ & 0.252 \\
\hline Renal disease & $49(7.5)$ & $9(8.7)$ & $58(7.7)$ & 0.836 \\
\hline Malignancy & $57(8.7)$ & $8(7.7)$ & $65(8.6)$ & 0.868 \\
\hline Cerebrovascular disease & $84(12.9)$ & $19(18.3)$ & $103(13.6)$ & 0.183 \\
\hline Alcohol use, no. (\%) & & & & 0.432 \\
\hline$<1$ time/mo & $392(60.1)$ & $56(53.8)$ & $448(59.3)$ & \\
\hline 1 time/mo to $<1$ time/wk & $139(21.3)$ & $24(23.1)$ & $163(21.6)$ & \\
\hline$\geq 1$ time/wk & $121(18.6)$ & $24(23.1)$ & $145(19.2)$ & \\
\hline Smoking, no. (\%) & $194(29.8)$ & $31(29.8)$ & $225(29.8)$ & 1.000 \\
\hline Antithrombotic use, no. (\%) & & & & 0.429 \\
\hline No & $380(58.3)$ & $56(53.8)$ & $436(57.7)$ & \\
\hline Antiplatelet & $191(29.3)$ & $29(27.9)$ & $220(29.1)$ & \\
\hline Warfarin & $66(10.1)$ & $15(14.4)$ & $81(10.7)$ & \\
\hline Both & $15(2.3)$ & $4(3.8)$ & $19(2.5)$ & \\
\hline \multicolumn{5}{|l|}{ Radiological findings, no. (\%) } \\
\hline Preop hematoma width $>20 \mathrm{~mm}$ & $287(44.0)$ & $51(49.0)$ & $338(44.7)$ & 0.342 \\
\hline Preop midline shift >10 mm & $242(37.1)$ & $44(42.3)$ & $286(37.8)$ & 0.328 \\
\hline \multicolumn{5}{|l|}{ Surgical details } \\
\hline Anesthesia, no. (\%) & & & & 1.000 \\
\hline General & $179(27.5)$ & $28(26.9)$ & $207(27.4)$ & \\
\hline Local & $473(72.5)$ & $76(73.1)$ & $549(72.6)$ & \\
\hline Side of op, no. (\%) & & & & 0.025 \\
\hline Unilat & $564(86.5)$ & $81(77.9)$ & $645(85.3)$ & \\
\hline Bilat & $88(13.5)$ & $23(22.1)$ & $111(14.7)$ & \\
\hline No. of bur holes, no. (\%) & & & & 0.441 \\
\hline 1 & $590(90.5)$ & $91(87.5)$ & $681(90.1)$ & \\
\hline 2 & $62(9.5)$ & $13(12.5)$ & $75(9.9)$ & \\
\hline Saline irrigation, no. (\%) & $84(12.9)$ & $13(12.5)$ & $97(12.8)$ & 1.000 \\
\hline
\end{tabular}


» CONTINUED FROM PAGE 1119

TABLE 1. Characteristics of patients with CSDH included in the study

\begin{tabular}{ccccc}
\hline Variable & No Recurrence & Recurrence & Total & $p$ Value \\
\hline Surgical details (continued) & & & & \\
\hline Drain insertion, no. (\%) & $652(100)$ & $104(100)$ & $756(100)$ & \\
\hline No. of days until drain removal, mean \pm SD & $2.7 \pm 0.9$ & $2.7 \pm 0.8$ & $2.7 \pm 0.9$ & 0.998 \\
\hline
\end{tabular}

$\mathrm{IQR}=$ interquartile range.

\section{Results}

\section{Clinical Characteristics}

We included 756 consecutive patients who underwent surgery for CSDH between January 1, 2004, and December 31,2014 , in one of the twin hospitals. The average age of the patients was 67.9 years, and $75.9 \%$ were men. The mean follow-up was $12.3 \pm 6.3$ months (median 11.5 months, interquartile range $9.0-14.5$ months).

During the 6-month follow-up, we identified 104 patients (13.8\%) with recurrence after surgery for CSDH. Thirty-four patients $(32.7 \%)$ were 75 years or older, and

TABLE 2. Univariate and multivariate analyses of the association between CSDH recurrence and various variables

\begin{tabular}{|c|c|c|c|c|}
\hline \multirow[b]{2}{*}{ Variable } & \multicolumn{2}{|c|}{ Univariate Analysis } & \multicolumn{2}{|c|}{ Multivariate Analysis } \\
\hline & $\mathrm{HR}(95 \% \mathrm{Cl})$ & $p$ Value & $\mathrm{HR}(95 \% \mathrm{Cl})$ & $\mathrm{p}$ Value \\
\hline Sex, M (vs F) & $1.26(0.78-2.03)$ & 0.346 & $1.30(0.80-2.11)$ & 0.285 \\
\hline \multicolumn{5}{|l|}{ Age, yrs } \\
\hline$<65$ & Reference & & & \\
\hline $65-74$ & $1.20(0.74-1.95)$ & 0.453 & $1.12(0.69-1.82)$ & 0.647 \\
\hline$\geq 75$ & $1.89(1.14-3.13)$ & 0.013 & $1.72(1.03-2.88)$ & 0.039 \\
\hline \multicolumn{5}{|l|}{$\mathrm{BMI}, \mathrm{kg} / \mathrm{m}^{2}$} \\
\hline 18.5-22.9, normal & Reference & & & \\
\hline$<18.5$, underweight & $1.56(0.86-2.85)$ & 0.147 & $1.61(0.87-2.95)$ & 0.128 \\
\hline 23.0-24.9, overweight & $1.44(0.84-2.45)$ & 0.185 & $1.41(0.83-2.41)$ & 0.207 \\
\hline$\geq 25.0$, obese & $1.81(1.09-3.00)$ & 0.021 & $1.73(1.03-2.93)$ & 0.040 \\
\hline Hypertension & $0.86(0.58-1.27)$ & 0.444 & & \\
\hline Diabetes & $1.38(0.92-2.07)$ & 0.123 & $1.25(0.82-1.89)$ & 0.300 \\
\hline Heart disease & $1.12(0.69-1.83)$ & 0.639 & & \\
\hline Liver disease & $1.47(0.85-2.54)$ & 0.169 & $1.58(0.91-2.73)$ & 0.103 \\
\hline Renal disease & $1.20(0.61-2.37)$ & 0.605 & & \\
\hline Malignancy & $0.87(0.42-1.79)$ & 0.706 & & \\
\hline Cerebrovascular disease & $1.50(0.91-2.46)$ & 0.112 & $1.47(0.89-2.43)$ & 0.130 \\
\hline \multicolumn{5}{|l|}{ Alcohol drinking } \\
\hline$<1$ time/mo & Reference & & & \\
\hline 1 time/mo to $<1$ time/wk & $1.20(0.75-1.94)$ & 0.448 & & \\
\hline$\geq 1$ time/wk & $1.36(0.85-2.20)$ & 0.205 & & \\
\hline Smoking & $1.01(0.67-1.54)$ & 0.955 & & \\
\hline \multicolumn{5}{|l|}{ Antithrombotic } \\
\hline No & Reference & & & \\
\hline Antiplatelet & $1.03(0.66-1.61)$ & 0.898 & & \\
\hline Warfarin & $1.44(0.82-2.55)$ & 0.209 & & \\
\hline Antiplatelet + warfarin & $1.69(0.61-4.66)$ & 0.311 & & \\
\hline Preop hematoma width $\geq 20 \mathrm{~mm}$ (vs $<20 \mathrm{~mm}$ ) & $1.21(0.82-1.78)$ & 0.333 & & \\
\hline Preop midline shift $\geq 10 \mathrm{~mm}$ (vs $<10 \mathrm{~mm})$ & $1.23(0.83-1.81)$ & 0.298 & & \\
\hline Anesthesia (general vs local) & $0.99(0.64-1.53)$ & 0.977 & & \\
\hline Side of op (bilat vs unilat) & $1.73(1.09-2.75)$ & 0.020 & $1.80(1.13-2.88)$ & 0.014 \\
\hline No. of bur holes (2 vs 1 ) & $1.28(0.72-2.29)$ & 0.408 & & \\
\hline Saline irrigation & $0.95(0.53-1.70)$ & 0.868 & & \\
\hline
\end{tabular}



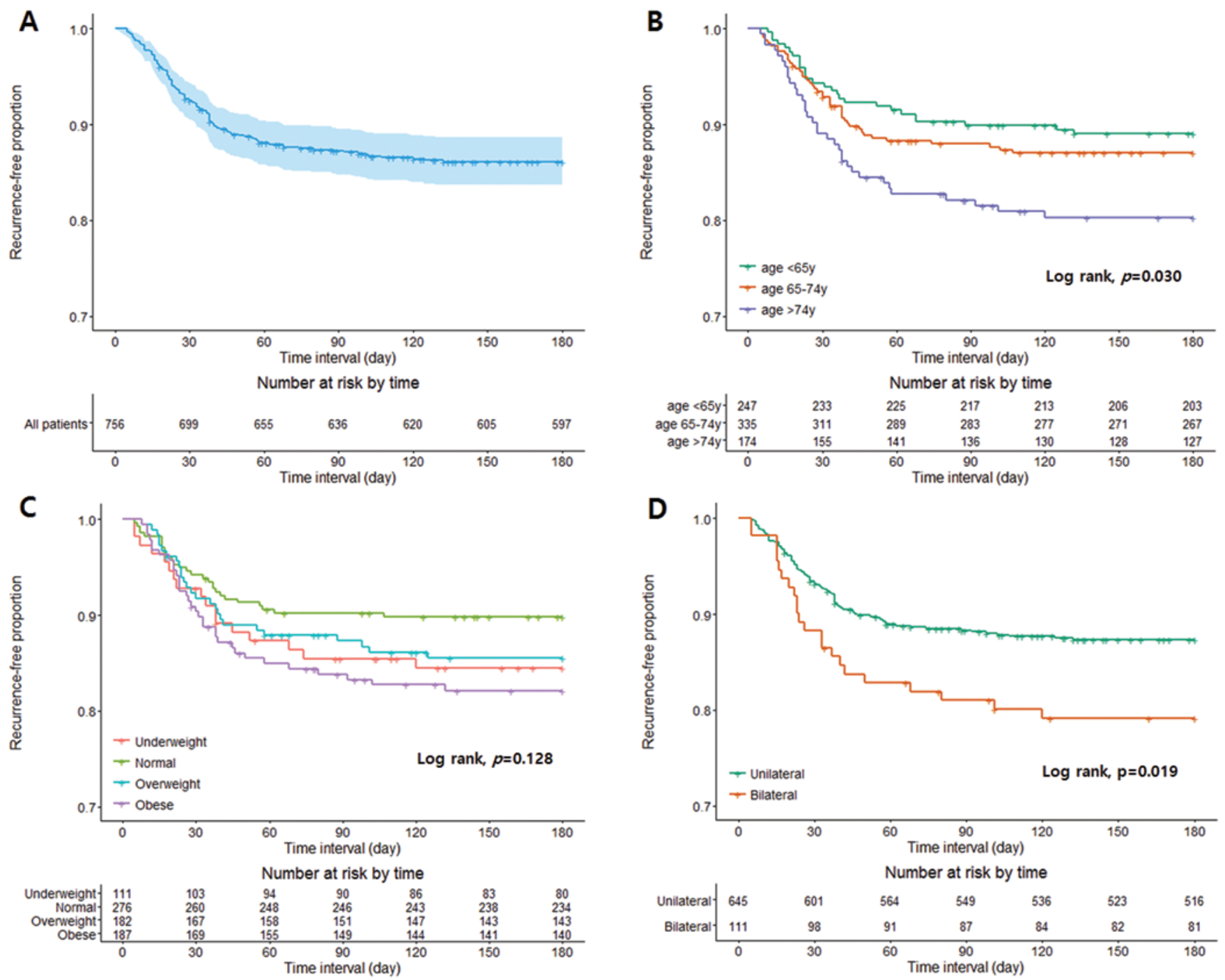

FIG. 1. A Kaplan-Meier curve with a log-rank test showing the recurrence-free proportion of patients 6 months after bur hole surgery based on the following risk factors for recurrence of CSDH: all patients $(\mathbf{A})$, age group (B), BMI (C), and side of operation (D). Figure is available in color online only.

there were 33 patients $(31.7 \%)$ with a BMI $\geq 25.0 \mathrm{~kg} / \mathrm{m}^{2}$ in the recurrence group. Twenty-three patients $(22.1 \%)$ in the recurrence group underwent bilateral operation. Further descriptive data are shown in Table 1.

\section{Risk Factors for Recurrence of CSDH}

We estimated the HRs for clinical, radiological, and surgical factors associated with recurrence after CSDH surgery. In a multivariate Cox regression analysis, which included sex, age group, BMI group, diabetes, liver disease, cerebrovascular disease, alcohol drinking, preoperative hematoma width, and side of operation, independent risk factors for recurrence were as follows: $\geq 75$ years age group (HR 1.72, 95\% CI 1.03-2.88; $\mathrm{p}=0.039$ ), obese group $\left(\mathrm{BMI} \geq 25.0 \mathrm{~kg} / \mathrm{m}^{2}\right)$ (HR 1.73, 95\% CI 1.03-2.93; $\mathrm{p}=0.040$ ), and bilateral operation group (HR 1.80, 95\% CI 1.13-2.88; $\mathrm{p}=0.014$ ) (Table 2). There were no interactions between BMI and age $(p=0.075)$, BMI and bilateral operation group $(p=0.246)$, or bilateral operation group and age $(\mathrm{p}=0.956)$.

The Kaplan-Meier curve, with log-rank tests showing the recurrence-free proportion of patients within 6 months after surgery for CSDH based on age group, BMI classification, and the side of operation is presented. The overall 6-month recurrence-free proportion of patients reached a plateau near $86 \%$ (Fig. 1A). Older patients ( $\geq 75$ years) had a greater risk of recurrence of CSDH (Fig. 1B). High BMI groups tended to have a higher recurrence rate (Fig. 1C). Patients with bilateral CSDH also had a greater risk of recurrence of CSDH (Fig. D). The multivariate hazard ratios adjusted for the 5 BMI groups are presented in Supplemental Table I. A Kaplan-Meier curve based on these BMI groups is shown in Supplemental Fig. I. Although there was a tendency toward a higher recurrence rate in patients with a BMI $\geq 27.5 \mathrm{~kg} / \mathrm{m}^{2}$, this was not statistically significant. However, the small number of patients with BMI $\geq$ $27.5 \mathrm{~kg} / \mathrm{m}^{2}$ might have lowered the statistical power. 
TABLE 3. Admission and last follow-up mRS scores based on risk factors for recurrence of $\mathrm{CSDH}$

\begin{tabular}{lccc}
\hline & \multicolumn{2}{c}{ mRS Score } & $p$ \\
\cline { 2 - 3 } \multicolumn{1}{c}{ Characteristic } & Admission & Last Follow-Up & Value \\
\hline All patients & $2.22 \pm 0.95$ & $1.06 \pm 1.09$ & $<0.001$ \\
\hline Age, yrs & & & \\
\hline$<65$ & $2.10 \pm 0.90$ & $0.87 \pm 0.96$ & $<0.001$ \\
\hline $65-74$ & $2.21 \pm 0.94$ & $0.96 \pm 0.95$ & $<0.001$ \\
\hline$\geq 75$ & $2.40 \pm 1.02$ & $1.49 \pm 1.38$ & $<0.001$ \\
\hline BMl classification, $\mathrm{kg} / \mathrm{m}^{2}$ & & & \\
\hline$<18.5$ & $2.26 \pm 0.93$ & $0.89 \pm 0.86$ & $<0.001$ \\
\hline $18.5-22.9$ & $2.11 \pm 0.93$ & $0.82 \pm 0.86$ & $<0.001$ \\
\hline $23.0-24.9$ & $2.25 \pm 0.99$ & $0.97 \pm 0.99$ & $<0.001$ \\
\hline$\geq 25.0$ & $2.33 \pm 0.96$ & $1.59 \pm 1.34$ & $<0.001$ \\
\hline Side of op & & & \\
\hline Unilat & $2.19 \pm 0.99$ & $1.01 \pm 1.11$ & $<0.001$ \\
\hline Bilat & $2.41 \pm 0.71$ & $1.30 \pm 0.98$ & $<0.001$ \\
\hline
\end{tabular}

* Values presented as the mean \pm SD.

\section{Clinical Outcomes of the Risk Factors for Recurrence}

The mean mRS score at admission and last follow-up was 2.22 and 1.06 in all patients, respectively, and the difference between the admission and the last follow-up mean mRS score was statistically significant in all patients and subgroups (Table 3). We found relatively higher last follow-up mean mRS scores in the older age group $(\geq$ 75 years, mean 1.49, SD 1.38), the higher BMI group ( $\geq$ $25.0 \mathrm{~kg} / \mathrm{m}^{2}$, mean 1.59 , SD 1.34), and the bilateral operation group (mean 1.30, SD 0.98). There was a higher mean $\mathrm{mRS}$ score on admission in overweight (BMI 23.0-24.9 $\left.\mathrm{kg} / \mathrm{m}^{2} ; \mathrm{p}=0.043\right)$ and obese $\left(\mathrm{BMI} \geq 25.0 \mathrm{~kg} / \mathrm{m}^{2} ; \mathrm{p}=0.036\right)$ groups compared with the normal weight group (BMI $18.5-22.9 \mathrm{~kg} / \mathrm{m}^{2}$ ) (Fig. 2).

In addition, we observed a significantly higher average mRS score on admission in the 65-74 years age group $(\mathrm{p}$ $=0.049)$ and the $\geq 75$ years age group $(p<0.001)$ relative to the $<65$ years age group. This association was also observed in the bilateral operation group $(p=0.026)$ compared with the unilateral group. At the last follow-up, obese patients $(p<0.001)$, those $\geq 75$ years old $(p<0.001)$, and patients who required a bilateral operation $(p=0.011)$ showed higher average mRS scores compared with the admission mRS scores of the same reference categories. The mean mRS scores with SDs at admission and at the last follow-up, stratified by the $5 \mathrm{BMI}$ groups, are presented in Supplemental Figure II.

\section{Discussion}

We observed an overall recurrence rate of $13.8 \%$ in patients with CSDH during a 6-month follow-up after bur hole surgery performed between January 1, 2004, and December 31, 2014, in 2 hospitals. Older patients ( $\geq 75$ years), obese patients $\left(\mathrm{BMI} \geq 25.0 \mathrm{~kg} / \mathrm{m}^{2}\right)$, and patients who required a bilateral operation had a 1.72-fold, 1.73-fold, and 1.80 -fold higher recurrence rate, respectively, after adjusting for all relevant variables. These risk factors for recur- rence also influenced clinical outcomes. Our study showed that older age, higher BMI, and bilateral operations were also associated with higher admission and follow-up mRS scores.

Our study showed that patients with factors associated with brain atrophy leading to poor reexpansion showed a higher recurrence rate. To the best of our knowledge, our study is the first to evaluate the association between the recurrence of CSDH and BMI. It is unclear whether higher $\mathrm{BMI}$ is related to the higher CSDH occurrence. However, our study showed that higher BMI was associated with recurrence of CSDH. The underlying pathophysiology is not clear. However, Raji et al. reported that a higher BMI was associated with lower brain volumes in overweight and obese elderly subjects, even when controlling for potential confounders such as age, sex, and race. ${ }^{28}$

In addition, Cherbuin et al. found that being overweight was associated with hippocampal atrophy. ${ }^{5}$ Other studies regarding BMI-associated brain atrophy support this finding. 10,16,25,34 Possible mechanisms include cortisol elevation, lack of exercise, and Type 2 diabetes. ${ }^{7,8,20}$ Fukuhara et al. reported that advanced age, brain atrophy, large hematomas, and prolonged compressed parenchyma influenced brain elasticity. ${ }^{9}$ Brains with high elasticity tend to reexpand poorly, and poor brain reexpansion is correlated with the recurrence of CSDH. ${ }^{21,35}$

Therefore, we hypothesized that brain atrophy and its association with high BMI might play a role in the underexpansion of the brain after surgery for CSDH, which subsequently increased the likelihood of CSDH recurrence. Although there was no statistical significance between $\mathrm{CSDH}$ recurrence and the underweight group, there were more recurrences in the underweight group compared with the normal BMI patient group. A recent study in Korea reported that being underweight was associated with low socioeconomic status and all-cause mortality. ${ }^{17}$ In addition, Silventoinen et al. found that being underweight is associated with a low social position, marginalization, and poor health behaviors. ${ }^{32}$ These factors may influence the higher recurrence rate to some extent in underweight patients relative to the patients with normal BMI in our study.

We observed a higher recurrence rate in the older age group. Previous studies reported that age was associated with poor brain expansion and recurrence of CSDH. 9,11,21,26,29,30 Ro et al. reported findings similar to ours, ${ }^{29}$ showing that there were more recurrences of CSDH in patients with no brain expansion or brain underexpansion after surgery for CSDH, and that this was associated with age and the duration of symptoms.

Bilateral hematoma was also associated with CSDH recurrence in our study. There have been several studies demonstrating bilateral hematoma to be a risk factor for the recurrence of CSDH. ${ }^{27,30,35}$ A study in Japan found that patients with bilateral CSDH tended to have previous brain atrophy, which led to poor brain reexpansion after operation. Poor brain reexpansion is thought to create the potential for the reaccumulation of a hematoma. Huang et al. reported that the recurrence rate of up to $28 \%$ observed for bilateral CSDH was higher than the $10 \%$ rate observed for unilateral CSDH. ${ }^{13}$ 
A
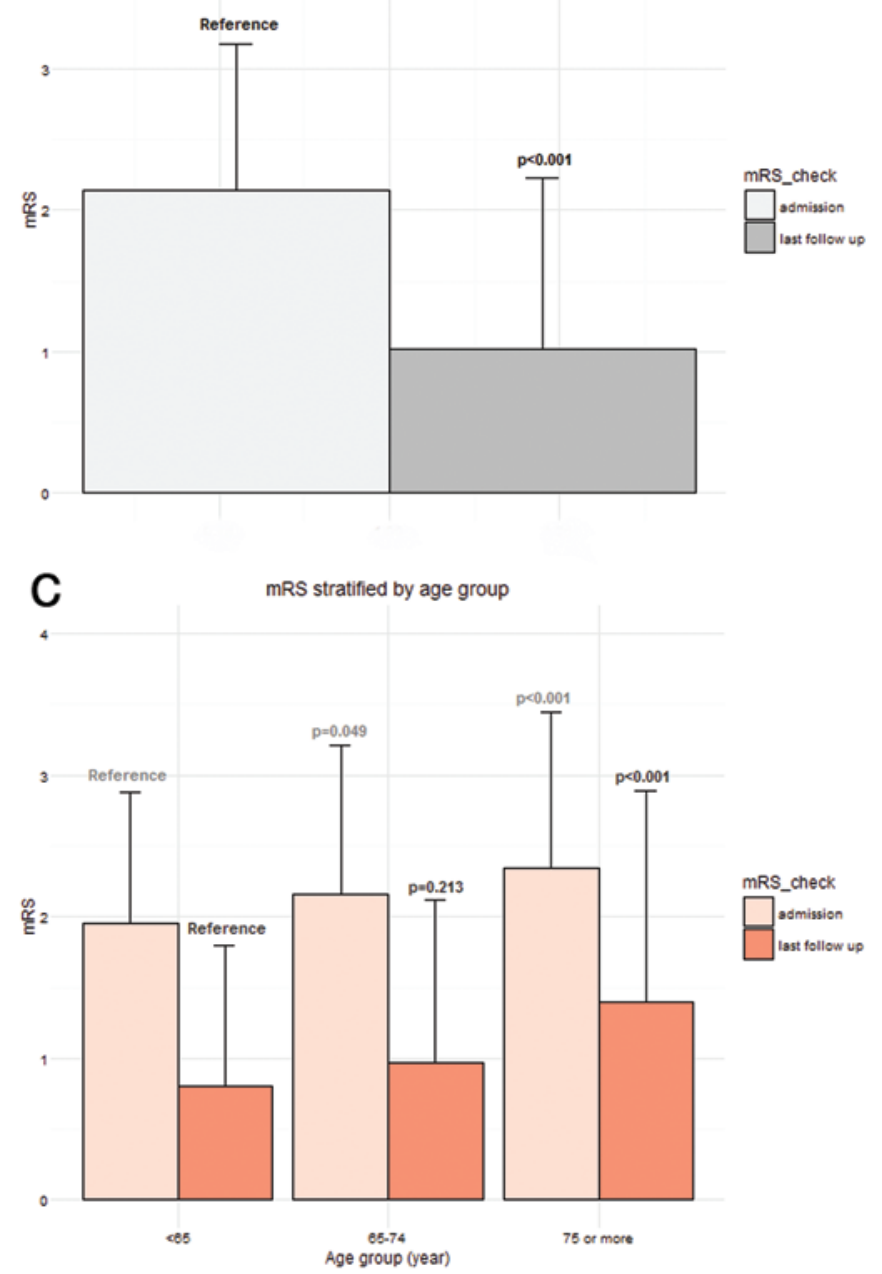

B

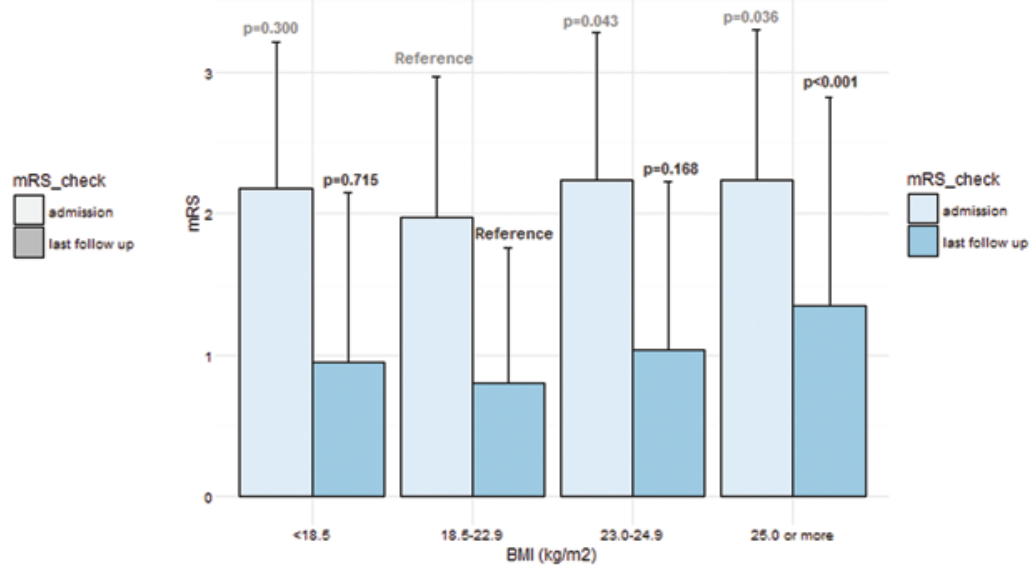

D
mRS stratified by BMI

mRS stratified by operation side

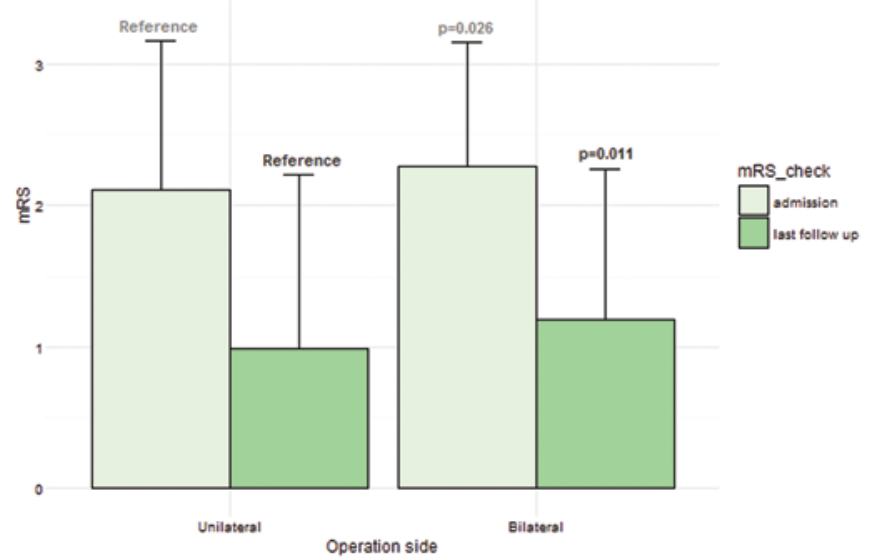

FIG. 2. Bar graphs with error bars showing the differences between the mRS score at admission and at the last follow-up based on the following risk factors for recurrence of CSDH: all patients (A), BMI (B), age group (C), and side of operation (D). Figure is available in color online only.

Lee found that the key determinant for development of CSDH is sufficient subdural space, in other words, cerebral atrophy. ${ }^{18}$ Yang et al. suggested that cerebral atrophy leads to tearing of the bridging veins between the rigidly fixed dura mater and the mobile arachnoid layer. ${ }^{39}$ A study using microscopy of postmortem material demonstrates that the subdural portion of the bridging veins has thinner vessel walls with less collagen, resulting in greater fragility than the subarachnoid portion. Therefore, these studies support the hypothesis that with greater cerebral atrophy, there is an increased likelihood of subsequent CSDH development.

Risk factors for CSDH recurrence also influenced clinical outcomes in the present study. A recent study in Korea demonstrated that older patients ( $\geq 75$ years) and patients with recurrent CSDH tended to have poorer mRS grades at 3 months. ${ }^{29}$ Previous studies demonstrated that an age threshold of 75 years was associated with unfavorable functional outcomes. ${ }^{3,19}$ Consequently, we hypothesized that patients with CSDH with previous brain atrophy have a higher recurrence rate, which is associated with poor brain reexpansion; this might result in less favorable clinical outcomes.

There were several limitations to our study. Due to the retrospective nature of the study, the findings may not be as accurate as those of a planned prospective study. We included only Korean patients in this study, which makes the generalizability of the results of this study limited. Our study population is leaner (that is, lower BMI) than those in most Western countries. Therefore, genetic variation and other underlying differences that exist between Asian and Western populations may confound the findings of this study.

The statistically significant effect of the bilateral operation group on recurrence might have some effect on the nonsignificant association between midline shift and CSDH recurrence. Therefore, further studies that include larger numbers of patients with unilateral CSDH are re- 
quired to more clearly investigate the association between CSDH recurrence and preoperative midline shift.

Reoperation was performed based on residual or recurrent CSDH on CT and persistent neurological deficits. However, the decision to reoperate was not strictly standardized due to the retrospective nature of the study. There was some variation in the period between admission and last follow-up in this study. Therefore, it is possible that higher mRS scores were observed in the short-term follow-up group compared with the long-term follow-up group.

\section{Conclusions}

We found significant associations between recurrence of CSDH and older age, higher BMI, and bilateral hematoma among patients who underwent bur hole surgery during the 11-year study period in twin hospitals. In addition, risk factors for recurrence of $\mathrm{CSDH}$ also influenced clinical outcomes. We expect these findings to be helpful for predicting prognosis for patients who undergo surgical treatment of CSDH. In addition, further prospective multicenter studies will be required to evaluate these findings.

\section{References}

1. Abouzari M, Rashidi A, Rezaii J, Esfandiari K, Asadollahi $\mathrm{M}$, Aleali $\mathrm{H}$, et al: The role of postoperative patient posture in the recurrence of traumatic chronic subdural hematoma after burr-hole surgery. Neurosurgery 61:794-797, 2007

2. Amirjamshidi A, Abouzari M, Eftekhar B, Rashidi A, Rezaii $\mathrm{J}$, Esfandiari K, et al: Outcomes and recurrence rates in chronic subdural haematoma. Br J Neurosurg 21:272-275, 2007

3. Borger V, Vatter H, Oszvald Á, Marquardt G, Seifert V, Güresir E: Chronic subdural haematoma in elderly patients: a retrospective analysis of 322 patients between the ages of 65-94 years. Acta Neurochir (Wien) 154:1549-1554, 2012

4. Chari A, Hocking KC, Broughton E, Turner C, Santarius T, Hutchinson PJ, et al: Core outcomes and common data elements in chronic subdural hematoma: a systematic review of the literature focusing on reported outcomes. J Neurotrauma 33:1212-1219, 2016

5. Cherbuin N, Sargent-Cox K, Fraser M, Sachdev P, Anstey KJ: Being overweight is associated with hippocampal atrophy: the PATH Through Life Study. Int J Obes 39:1509-1514, 2015

6. Chon KH, Lee JM, Koh EJ, Choi HY: Independent predictors for recurrence of chronic subdural hematoma. Acta Neurochir (Wien) 154:1541-1548, 2012

7. Climie RED, Moran C, Callisaya M, Blizzard L, Sharman JE, Venn A, et al: Abdominal obesity and brain atrophy in Type 2 diabetes mellitus. PLoS One 10:e0142589, 2015

8. Colcombe SJ, Erickson KI, Raz N, Webb AG, Cohen NJ, McAuley E, et al: Aerobic fitness reduces brain tissue loss in aging humans. J Gerontol A Biol Sci Med Sci 58:176-180, 2003

9. Fukuhara T, Gotoh M, Asari S, Ohmoto T, Akioka T: The relationship between brain surface elastance and brain reexpansion after evacuation of chronic subdural hematoma. Surg Neurol 45:570-574, 1996

10. Gazdzinski S, Kornak J, Weiner MW, Meyerhoff DJ: Body mass index and magnetic resonance markers of brain integrity in adults. Ann Neurol 63:652-657, 2008

11. Gelabert-González M, Iglesias-Pais M, García-Allut A, Martínez-Rumbo R: Chronic subdural haematoma: surgical treatment and outcome in 1000 cases. Clin Neurol Neurosurg 107:223-229, 2005

12. Guha D, Coyne S, Macdonald RL: Timing of the resumption of antithrombotic agents following surgical evacuation of chronic subdural hematomas: a retrospective cohort study. J Neurosurg 124:750-759, 2016

13. Huang YH, Yang KY, Lee TC, Liao CC: Bilateral chronic subdural hematoma: what is the clinical significance? Int J Surg 11:544-548, 2013

14. Jih J, Mukherjea A, Vittinghoff E, Nguyen TT, Tsoh JY, Fukuoka Y, et al: Using appropriate body mass index cut points for overweight and obesity among Asian Americans. Prev Med 65:1-6, 2014

15. Jung YG, Jung NY, Kim E: Independent predictors for recurrence of chronic subdural hematoma. J Korean Neurosurg Soc 57:266-270, 2015

16. Kiliaan AJ, Arnoldussen IAC, Gustafson DR: Adipokines: a link between obesity and dementia? Lancet Neurol 13:913923, 2014

17. Kim NH, Lee J, Kim TJ, Kim NH, Choi KM, Baik SH, et al: Body mass index and mortality in the general population and in subjects with chronic disease in Korea: a nationwide cohort study (2002-2010). PLoS One 10:e0139924, 2015

18. Lee KS: Chronic subdural hematoma in the aged, trauma or degeneration? J Korean Neurosurg Soc 59:1-5, 2016

19. Leroy HA, Aboukaïs R, Reyns N, Bourgeois P, Labreuche J, Duhamel A, et al: Predictors of functional outcomes and recurrence of chronic subdural hematomas. J Clin Neurosci 22:1895-1900, 2015

20. Lupien SJ, de Leon M, de Santi S, Convit A, Tarshish C, Nair $\mathrm{NP}$, et al: Cortisol levels during human aging predict hippocampal atrophy and memory deficits. Nat Neurosci 1:69-73, 1998

21. Mori K, Maeda M: Surgical treatment of chronic subdural hematoma in 500 consecutive cases: clinical characteristics, surgical outcome, complications, and recurrence rate. Neurol Med Chir (Tokyo) 41:371-381, 2001

22. Nakaguchi H, Tanishima T, Yoshimasu N: Factors in the natural history of chronic subdural hematomas that influence their postoperative recurrence. J Neurosurg 95:256-262, 2001

23. Ohba S, Kinoshita Y, Nakagawa T, Murakami H: The risk factors for recurrence of chronic subdural hematoma. Neurosurg Rev 36:145-150, 2013

24. Pang CH, Lee SE, Kim CH, Kim JE, Kang HS, Park CK, et al: Acute intracranial bleeding and recurrence after bur hole craniostomy for chronic subdural hematoma. J Neurosurg 123:65-74, 2015

25. Pannacciulli N, Del Parigi A, Chen K, Le DSNT, Reiman EM, Tataranni PA: Brain abnormalities in human obesity: a voxel-based morphometric study. Neuroimage 31:1419-1425, 2006

26. Pilitsis J, Atwater B, Warden D, Deck G, Carroll J, Smith J, et al: Outcomes in octogenarians with subdural hematomas. Clin Neurol Neurosurg 115:1429-1432, 2013

27. Probst C: Peritoneal drainage of chronic subdural hematomas in older patients. J Neurosurg 68:908-911, 1988

28. Raji CA, Ho AJ, Parikshak NN, Becker JT, Lopez OL, Kuller LH, et al: Brain structure and obesity. Hum Brain Mapp 31:353-364, 2010

29. Ro HW, Park SK, Jang DK, Yoon WS, Jang KS, Han YM: Preoperative predictive factors for surgical and functional outcomes in chronic subdural hematoma. Acta Neurochir (Wien) 158:135-139, 2016

30. Robinson RG: Chronic subdural hematoma: surgical management in 133 patients. J Neurosurg 61:263-268, 1984

31. Santarius T, Kirkpatrick PJ, Ganesan D, Chia HL, Jalloh I, Smielewski P, et al: Use of drains versus no drains after burr-hole evacuation of chronic subdural haematoma: a randomised controlled trial. Lancet 374:1067-1073, 2009 
32. Silventoinen K, Magnusson PKE, Tynelius P, Batty GD, Rasmussen F: Association of body size and muscle strength with incidence of coronary heart disease and cerebrovascular diseases: a population-based cohort study of one million Swedish men. Int J Epidemiol 38:110-118, 2009

33. Steyerberg E: Clinical Prediction Models: A Practical Approach to Development, Validation, and Updating. New York: Springer, 2009

34. Taki Y, Kinomura S, Sato K, Inoue K, Goto R, Okada K, et al: Relationship between body mass index and gray matter volume in 1,428 healthy individuals. Obesity (Silver Spring) 16:119-124, 2008

35. Torihashi K, Sadamasa N, Yoshida K, Narumi O, Chin M, Yamagata S: Independent predictors for recurrence of chronic subdural hematoma: a review of 343 consecutive surgical cases. Neurosurgery 63:1125-1129, 2008

36. World Health Organization: The Asia-Pacific Perspective: Redefining Obesity and Its Treatment. Manila: World Health Organization Western Pacific Region, 2000 (http:// www.wpro.who.int/nutrition/documents/Redefining_obesity/ en/) [Accessed October 13, 2016]

37. Yamamoto H, Hirashima Y, Hamada H, Hayashi N, Origasa $\mathrm{H}$, Endo $\mathrm{S}$ : Independent predictors of recurrence of chronic subdural hematoma: results of multivariate analysis performed using a logistic regression model. J Neurosurg 98:1217-1221, 2003

38. Yamashima T, Friede RL: Why do bridging veins rupture into the virtual subdural space? J Neurol Neurosurg Psychiatry $47: 121-127,1984$
39. Yang AI, Balser DS, Mikheev A, Offen S, Huang JH, Babb $\mathrm{J}$, et al: Cerebral atrophy is associated with development of chronic subdural haematoma. Brain Inj 26:1731-1736, 2012

\section{Disclosures}

The authors report no conflict of interest concerning the materials or methods used in this study or the findings specified in this paper.

\section{Author Contributions}

Conception and design: Ryu. Acquisition of data: Han. Analysis and interpretation of data: Han. Drafting the article: Han. Critically revising the article: $\mathrm{CH}$ Kim, JM Kim, Cheong, Yi. Reviewed submitted version of manuscript: CH Kim, JM Kim, Cheong, Yi. Statistical analysis: Han. Radiologic confirmation: Cheong, Yi.

\section{Supplemental Information}

Online-Only Content

Supplemental material is available with the online version of the article.

Supplemental Material. https://thejns.org/doi/suppl/10.3171/ 2016.8.JNS16867.

\section{Correspondence}

Je Il Ryu, Department of Neurosurgery, Hanyang University Guri Hospital, 153 Gyeongchun-ro, Guri 471-701, Gyonggi-do, Korea. email: ryujeil@hanmail.net. 